\title{
Socio-spatial Perspectives on Open-Plan versus Cellular Offices
}

Kerstin Sailer, The Bartlett School of Architecture, University College London, k.sailer@ucl.ac.uk

Matt Thomas, The Department of Strategy and International Business, The Business School, University of Birmingham, m.a.thomas.2@bham.ac.uk

\begin{abstract}
Purpose | This research provides a new perspective on the long-standing debate of open-plan versus cellular offices. It analyzes the effects of workplace layouts on organizational outputs such as innovation, efficiency and privacy by considering the physical space of an organization alongside its organizational structure. This sociospatial approach draws on correspondence theory originating from space syntax to understand the potential for unplanned encounters between diverse groups of people.
\end{abstract}

Design/methodology/approach | Three different organizations are studied, two openplan and one cellular office. Floor and seating plans are analyzed to calculate the degree of correspondence between spatial and conceptual closeness of people. Demands for each organization are derived from semi-structured interviews and publicly available information.

Findings | The three studied organizations present very different degrees of openness towards others in ways that challenge conventional views of cellular and open-plan offices. In each case though the degree of correspondence matches the demands placed on the organization, hence providing relatively good fit between organization and interior environment.

Research limitations/implications | A larger sample of open-plan and cellular offices would be useful to consider in further research.

Practical implications | Managers can use the concept of correspondence to generate the appropriate degree of unplanned encounters between the right sets of people in order to achieve best organization-environment fit.

Originality/value | The main innovation of this paper lies in its socio-spatial approach, considering physical space alongside managerial organizational choices.

\section{Keywords}

Open-plan office; cellular office; space syntax; organizational chart; seating plan; innovation; efficiency; privacy; unplanned encounter; organization-environment fit; 


\section{Introduction}

The spatial layout of workplaces, mainly discussed as open-plan versus cellular offices is a highly debated topic, not only in scholarly work, but also in industry and the public domain. A flurry of news articles appeared in mainstream media in 2018 and 2019 discussing the pitfalls of open-plan offices, including well known complaints such as their lack of privacy (Financial Timesi), increased noise and stress levels (Vice ${ }^{\mathrm{ii}}$ ), their demotivational character (The Guardian ${ }^{\mathrm{iii}}$ ), their failure to increase collaboration (Forbes ${ }^{\text {iv }}$ ) but also less widely known aspects like their apparent sexism (Fast Company ${ }^{v}$ ).

While it seems at first sight that there is consensus on the best way to organize office space as far as the general public is concerned (and that is not open-plan), the matter is not quite so easily settled. Looking not just at the public perception, but at industry practices and standards, as well as at the scholarly discourse, the story becomes more complex with contradictions, paradoxes and opposing viewpoints being the norm.

This paper wants to highlight but a few of those paradoxes as background to its own research enquiry following the approach of articulating tensions as suggested in the paradox literature (Lewis, 2000, Smith and Lewis, 2011).

\section{The paradox of effectiveness}

Professionals in the construction industry, such as corporate real estate managers, architects, interior designers, consultants, space planners and facility managers are aiming to provide organizations with attractive and effective workspaces. Yet only $61 \%$ of office occupants in one of the largest workplace satisfaction surveys with more than 500,000 participants concur that their workplace allows them to work productively (Leesman, 2019). At the same time only 15\% of the global workforce are actively engaged in their workplace (Gallup, 2017) with the physical environment of work clearly playing a role in workplace satisfaction. So how can it be that offices are continuing to be designed so ineffectively?

\section{The paradox of perception and reality}

Looking into the public perception of office layouts, the evidence from news articles and media coverage overwhelmingly suggests that open-plan offices are hated by occupants with a 2013 headline taking a radical stance and claiming that open-plan was "devised by Satan in the deepest caverns of hell" (The Guardianvi). Despite this apparent agreement in public perception, open-plan offices remain the preferred model for industry, specifically in the UK, where open-plan offices have become standard across many industries. A recent Savills report on the state of European workplaces concluded that the provision of open-plan environments increased across all of Europe with the UK leading the open-plan league table with $73 \%$ of sampled workers accommodated in open-plan versus an average of $51 \%$ across Europe (Savills, 2019). Even those industries once considered having clear preferences and propensities towards cellular office accommodation such as academia are slowly transformed into open-plan accommodation (Van Marrewijk and Van den Ende, 2018) despite pleas by users (Bari, 2015). So why does industry continue to provide open-plan offices if users repeatedly reject them? 


\section{The paradox of progress}

Progress is often viewed as a linear and continuous sequence. In this view, cellular offices are often seen as traditional setups, where hierarchies thrive and power relations and status are built into the fabric of the office, or in the words of Hillier and Hanson (1984, p. 195) "relative asymmetry resulting from (...) subdivision guarantees the status of inhabitants" in cellular office environments. In contrast, open-plan offices are considered modern and forward looking. Yet the history of the office (CarusoStJohnArchitects, 2014) shows how phases of enclosure and openness alternated over time, for instance the Larkin administration building by Frank Lloyd Wright (1903) organized work in open-plan, whereas the Seagram building by Ludwig Mies van der Rohe, completed in 1958 offered cellular offices. Therefore, the assumption that newer office buildings will be open-plan, whereas older office buildings will be cellular does not hold up against scrutiny.

The paradox of progress is nowhere as clear when discussing one particular office layout, that of cubicles. Robert Propst, an American designer and researcher working for the furniture company Herman Miller is acknowledged as the inventor of the cubicle system in the 1960s. Propst critiqued existing office structures as not fit for purpose: "for most of us, the office is a place where we go to suffer a variety of environmental accidents. (...) Most of the time (...) they are bad accidents, wasters of effectiveness, vitality, health and motivation" (Propst, 1968, p. 9). Based on his own research into the nature of human needs such as privacy and connection, as well as the operating principles of office work, he invented the 'Action Office', a modular and flexible system of partitions meant to enable users to work more freely and effectively. The cubicle was born. Intended as progress towards a more modern and humanized workplace combining the best ideas from open-plan and cellularized environments, it quickly became clear that cubicles did not live up to the expectations and instead were considered least preferable by occupants (Kim and de Dear, 2013).

Therefore, progress is not necessarily a linear process where newer workplace configurations automatically provided superior office accommodation.

\section{The paradox of inconsistencies}

Last but not least, the paradox of inconsistencies is of most interest to scholars in the field. Research on physical workplaces and organizational outcomes can look back on a longstanding tradition highlighting how different aspects of office layout play a crucial role for how work is organized (Steele, 1973, Becker, 1981, Pfeffer, 1982, Davis, 1984, Sundstrom, 1986).

Yet decades later researchers are still grappling with continued inconsistencies when it comes to the effects of open-plan offices. An overview of studies from the 1960s to the 1980s on organizations moving to open-plan illustrates this clearly with roughly a third of studies resulting in positive outcomes, a third in communication decreases and another third in inconclusive results (Sailer and Penn, 2009, Sailer, 2010).

Other studies confirmed this conundrum. On the one hand scholars found that moves into more open-plan environments were fraught with negative implications such as social withdrawal and increasing reliance on electronic communication (Bernstein and Turban, 2018) or active avoidance of new collaborations (Irving et al., Forthcoming). On the other hand, studies reported positive implications of open-plan layouts, specifically higher levels of unplanned encounter due to lines of sight and 
temporary proximity between users (Backhouse and Drew, 1992), ease and speed of information exchange (Mark, 2002), relationship building (Beunza and Stark, 2004), and higher degrees of awareness for workers to know what others are doing and their ability to identify critical events quickly, hence the space acting like a 'seismograph' (Tsen, 2001).

Scholars have worked with different potential explanations for these inconsistencies. Some argued that our continued inability to understand workplaces is due to an overall lack of understanding (Gieryn, 2002) and disparate discourses across scholarly disciplines (Clegg and Kornberger, 2006, Price, 2007). Others made a case that the high complexity of the research topic and its multiple layers of mutual influence and entanglement were at the heart of the problem (Sailer, 2010), therefore requiring more nuanced and detailed research of the tensions and trade-offs in organizations (Elsbach and Pratt, 2007), but also focusing research on the underlying mechanisms and implications (Ashkanasy et al., 2014).

This paper proposes that the reason for our continuing paradoxical relationship with the physical environment of work lies in a failure to consider the office as a social and spatial reality at the same time. While the approach of investigating both social and spatial worlds equally and concurrently is shared by scholars interested in sociomateriality (Van den Ende et al., 2020, Orlikowski and Scott, 2008), the perspective of this paper is a quantitative one. Rather than focusing on work practices and their social and material entanglement by means of detailed qualitative observation and analysis, a method and metric is suggested of quantifying the degree of boundary maintenance in organizations and thereby how social and spatial realities and solidarities are co-constituted. This is based on the architectural approach of space syntax (Hillier and Hanson, 1984) and in particular the theory of correspondence and non-correspondence, which will be introduced in the following chapter. But first it will be argued why this new way of seeing is required.

\section{Required: A New Way of Seeing}

For decades now scholars have bemoaned the gaps in research on the physical environment of work (Sundstrom et al., 1980, Elsbach and Pratt, 2007), especially from the perspective of management research. However, very recently a resurgence of interest in the spatial context of organizations can be noted by scholars in sociology (Small and Adler, 2019) and organizational behavior alike (Ayoko and Ashkanasy, 2020).

In this context of a renewed interest in how the physical environment of work affects behavior in organizations, a series of oversights in the discourse can be observed.

Firstly, a detailed appreciation of workplace layout is required. Not every open-plan office is the same; they differ not just in their size, their shape of floor plates and numbers of floors (thus giving rise to a particular configuration), but there is enormous variation in detailed arrangements including access to daylight, numbers of people sharing a floor and other resources such as a kitchen, numbers of people in a single space, openness of main circulation routes towards workspaces, degree and height of partitioning, quality of partitioning (including acoustical properties), etc. While this sounds obvious, extant research has conflated or downplayed those differences. For instance, Bernstein and Turban (2018) have not included floor plans or a detailed description of office configuration in their paper, hence it is difficult to 
contextualize their findings. Other scholars have not made explicit enough distinctions between US-style cubicles and open-plan offices without any partitions; for instance, Kim and de Dear $(2013,2020)$ analyzed the trade-off between the positive effect of easing interaction and the negative impact on privacy in open-plan offices, but clubbed three different types of 'open-plan' together, i.e. high walled cubicles, low walled cubicles and open-plan without partitions. Only $7 \%$ of their UScentric sample were open-plan offices with no partitions while a majority was high partition cubicles (38\%). Thus, well-known issues of cubicles are communicated as if they applied equally to fully open-plan layouts, which might not be the case.

Secondly, how a given workplace layout is brought to life by managerial decisions is often overlooked. Coined as 'configuration-in-use' (Sailer, 2010) the decision where to place central resources such as the printers, coffee machines or central administrators can play a crucial role in how organizational life will emerge within a given setting. A common strategy of organizations might be to provide central resources that bring everyone together for example a larger communal hub with kitchen facilities and seating. In that case organizations might choose to provide only bare necessities in micro-kitchens dotted around a floor (such as a water cooler, or a kettle) in order to incentivize movement of users to more attractive offerings (such as good coffee). With this strategic choice chance encounters will be raised and particular affordances for interaction will be created (Fayard and Weeks, 2007).

The most obvious example of managerial decision-making in the context of how to make use of a spatial layout however is the seating plan. Typically, organizations choose to cluster teams with similar functions together, yet a distribution strategy has been proposed to foster innovation and cross-functional fertilization of ideas (Peters, 1990). Again, those decisions are meaningful since they change the opportunities for workplace users to meet and see others, not just in quantities (how many colleagues are seen), but also regarding equal or unequal distributions of chances (which colleagues are seen / not seen) and quality of encounters (which type of conversations are fostered / impeded).

Thirdly, additional attention is needed for the aspect of the fit between an organization and its interior physical environment. If a workplace layout supports openness, but is inhabited by an organization thriving on privacy, concentration and individual working such as academia, it is likely that occupants will report low levels of satisfaction. Likewise, a highly partitioned and cellularized environment might cause frustration and inefficiencies if it accommodates an organization requiring speedy information exchange, such as a media company. While scholars have investigated the person-environment fit in workplaces (Appel-Meulenbroek et al., 2020), there is little research on the organization-environment fit regarding the interior workplace layout. There is a rich literature on organization-environment fit in management research that covers fit between the organization and the external environment (Aldrich, 1979), and the fit between the organization and internal structures and management processes (Miles and Snow, 1984), however this does not extend to the layout of the internal workplace.

Therefore, it is not just the spatial layout of a workplace that matters for organizational behavior, but equally the way in which the layout is strategically utilized by a particular organization and how the layout interplays with organizational culture and structure. This leads us to suggest the socio-spatial theory of correspondence, initially introduced by Hillier and Hanson (1984) as a way to 
understand the implications of a particular environment - be it open-plan or cellular in more detail.

\section{The Socio-Spatial Theory of Correspondence}

The workplace environment is important to organizations because of the impact on social relationships and the interactions that result. In the workplace, people relate to each other in two fundamentally different ways: spatially and conceptually (Sailer and Penn, 2009). Spatial relations are generated by close proximity and visibility of others, such as colleagues that might share a desk cluster or room. Conceptual relations are those with similar others, for example, with the people who work in the same team or department in an organization structure. As a result, to analyze the importance of the workplace environment on organizations the impact of both spatial and conceptual relations needs to be understood.

Originally proposed by Hillier and Hanson (1984), the concept of correspondence describes the overlap between spatial and social relations. A correspondent system is one with a high degree of overlap between spatial and social relations, so that people in close spatial proximity are also conceptually close. An obvious example for a correspondent system is an office where each department is located together but separated spatially from other departments. By contrast, a non-correspondent system is one where little overlap is evident, for example, "jamming people from disparate functions together in the same room" (Peters, 1990, p. 23) would have the effect of creating a non-correspondent system in an organizational context.

The categorization of socio-spatial systems as either correspondent or noncorrespondent is important because they have very different characteristics. Correspondent socio-spatial systems are characterized by a staticness of the population, which results in the conservation of "roles and positions, of social praxes and rituals, of statuses and identities" (Hillier, 1996, p. 196). By contrast, in noncorrespondent systems the "conditions exist for all kinds of generation - new relationships, new ideas, new products and even knowledge" (Hillier and Penn, 1991, p. 29).

The concept of correspondence has been developed into an objective measure (Sailer and Thomas, 2019) by which the socio-spatial systems of organizations can be compared.

\section{Methods}

In this paper a series of measurements is used (as detailed below), which were then applied to different organizations occupying a variety of open and cellular office environments.

\section{Study Context}

Three organizations were selected as the focus of this research: a research institute specializing in theoretical physics located in Germany ('Institute'); the head office of a regional law firm located in the UK ('Law'); and the head office of a US based technology firm that designs and manufactures products for the financial services industry ('Technology'). 
These organizations were selected on the basis of two criteria: that the demands placed on them by the nature of the work and their competition were substantially different; that the three organizations had socio-spatial environments that were also substantially different. The differences in socio-spatial structure were assessed by considering the dominant spatial layout utilized and by the choices made in locating teams within that layout.

'Institute' used cellular offices within which both regular staff and visiting researchers were located. Offices were assigned based on availability rather than any team structures. As a result, staff and visitors to the institute were relatively randomly distributed.

'Law' had moved from cellular offices to open-plan offices with cubicles three years before the period of research. Staff were located functionally whereby teams of lawyers specializing in the same areas of law were located on the same or adjacent desk clusters.

'Technology' used open-plan offices with no cubicles. Staff were located crossfunctionally whereby groups of people from different departments on the organization chart were clustered together.

\section{Measures}

With the aim of understanding the organization-environment fit the demands of the organization are examined and then the likelihood of the environment being able to meet those demands.

\section{Measuring the demands placed on the organization}

To understand the demands placed on each organization studied, they are evaluated against three criteria derived from the literature and described in the introduction to this paper: (1) The degree to which innovation is critical to the organization (Peters, 1990); (2) The degree to which efficiency is critical (Leesman, 2019); and (3) The importance of privacy/concentration to employees (Sundstrom et al., 1980). Each of the three criteria characterize the demands placed on the organization and are known to be affected by the socio-spatial environments in which those organizations operate.

Each measure was evaluated on a scale from 1 to 5 where 1 represented the criterion not valued highly by the organization and 5 that the criterion was valued highly.

\section{Measuring the socio-spatial environment}

The measure for socio-spatial correspondence developed by Sailer and Thomas (2019) is used to describe the socio-spatial environment in each of the organizations studied. The measure of socio-spatial correspondence is used to explain the profile of unplanned interaction to be found in each organization (Thomas, 2019).

Based on the measure of Yule's $Q$, which describes the association between two sets of dichotomous variables (spatially close or not close, conceptually close or not 
close), each calculation of correspondence gives a value between -1 and +1 . The variables are defined as follows: Spatial closeness between $A$ and $B$ was defined as A being proximate to a colleague $B$ at any point of the day as a result of both the desk location of $A$ and their everyday shortest paths (to meeting rooms, entrances, tea points etc.) that led past the desk of $B$. Those paths were simulated based on knowledge of popular destinations and movement routes gathered through ethnographic observations and interviews. Therefore, proximity between $A$ and $B$ signifies a face-to-face interaction opportunity. Conceptual closeness was defined as A and B being part of the same research group (in 'Institute') or the same department (in 'Law' and 'Technology'). Closeness is measured for each pair of individuals and then aggregated as count data per organization ${ }^{\text {vii. }}$

A value of +1 for Yule's $Q$ denotes a perfect positive association between spatial and conceptual relations, in other words, that people who are located together spatially are also grouped together in the organization chart. In terms of social interaction, such a value would suggest that team members interact with each other but not with other teams.

A value of 0 (zero) denotes non-correspondence where the overlap between spatial and conceptual relations are random. Such a value suggests that social interaction would also be random, and each member of staff would be as likely to interact with a member of other teams as their own.

A value of -1 denotes perfect negative correspondence where there is no overlap between people located together and those with whom they are grouped in the organization chart. Such a value suggests that staff would never interact with their own teams.

Two measures for correspondence are used for each organization. The first measure of correspondence refers to overlap in spatial and conceptual relations by groups or teams defined by the organization chart. The second measure refers to the overlap in spatial and conceptual relations between staff and visitors to each organization, i.e. people belonging to other organizations and coming to site temporarily for particular purposes (e.g. for a meeting, as contractors, or visiting scientists). This is referred to as internal and external correspondence respectively.

\section{Data Collection}

Data required to assess the demands placed on the organization was collected through semi-structured interviews with employees and through publicly available information about the competitive environment in which each operated (including strategy statements in annual reports, company websites and other publicly available company documents).

Data for measuring the socio-spatial environment was obtained from detailed scale drawings of the office layouts, organization charts and the seating plans of staff.

Data for 'Institute' was collected in 2006 by the first author of this paper, while data for 'Law' and 'Technology' was collected in 2015 by the second author. 


\section{Results}

The results are presented in three sections. The first reports on findings relating to the demands placed on each of the organizations studied. The second reports on the socio-spatial environment found in each. The third section describes the fit between the demands placed on each organization and their socio-spatial environments.

\section{Demands placed on each organization}

The demands placed on each organization were found to be substantially different. 'Institute' appeared to value innovation and genuine novelty in their research above all else. It was an organization proud to have hosted Nobel prize winners and one that was measured competitively on the originality of its research output. The director of the Institute remarked that "the success of [the] organization lies mainly in the creation of the right climate, where new ideas and developments have best chances to prosper."viii Equally, privacy was important to the scientists whose work included the need to read, write, think and calculate. In interviews efficiency in research was rarely mentioned, suggesting that the originality of research was valued above the efficiency with which it was produced. This profile of the demands placed on 'Institute' is summarized in table 1.

\begin{tabular}{|l|l|l|l|l|l|l|}
\hline & \multicolumn{2}{|c|}{ Innovation } & \multicolumn{2}{|c|}{ Efficiency } & & Privacy \\
\hline Institute & 5 & $\begin{array}{l}\text { High premium } \\
\text { placed on } \\
\text { original research }\end{array}$ & 1 & $\begin{array}{l}\text { Originality of } \\
\text { research } \\
\text { valued above } \\
\text { efficiency of } \\
\text { production }\end{array}$ & 5 & $\begin{array}{l}\text { Ability to } \\
\text { concentrate at } \\
\text { a premium }\end{array}$ \\
\hline Law & 2 & $\begin{array}{l}\text { Reliability, } \\
\text { accuracy and } \\
\text { expertise valued } \\
\text { higher than } \\
\text { originality }\end{array}$ & 5 & $\begin{array}{l}\text { Efficiency } \\
\text { valued highly } \\
\text { by clients }\end{array}$ & 4 & $\begin{array}{l}\text { Confidentiality } \\
\text { of clients and } \\
\text { ability to } \\
\text { concentrate } \\
\text { valued }\end{array}$ \\
\hline Technology & 4 & $\begin{array}{l}\text { Product } \\
\text { innovation } \\
\text { important to } \\
\text { competitive } \\
\text { position }\end{array}$ & 4 & $\begin{array}{l}\text { Efficiency in } \\
\text { design and } \\
\text { manufacturing } \\
\text { processes } \\
\text { valued highly }\end{array}$ & 1 & $\begin{array}{l}\text { Benefits of } \\
\text { random } \\
\text { interaction } \\
\text { valued above } \\
\text { privacy }\end{array}$ \\
\hline
\end{tabular}

Table 1: Demands placed on each organization

In contrast to 'Institute', efficiency was highly valued by 'Law' where they competed with other law firms for the same clients. Clients expected the work to be conducted accurately and efficiently so that their fees were kept to a minimum. Relative to efficiency, creativity was not valued as highly within 'Law' as their advice to clients was expected to be accurate and reliable rather than innovative. The managing partner commented "our sector is getting more and more price competitive, yet to retain the best lawyers in the field we have to maintain and grow profitability. This means we have to do things more efficiently than anyone else". However, like the scientists in 'Institute' the lawyers valued privacy in order to maintain confidentiality of their clients and to aid concentration in producing legal advice efficiently. 
'Technology' competed on the basis of constant innovation in their products and those products needed to be brought to market in a timely manner in order to stay ahead of competition. Online publisher FastCompany rank 'Technology' as one of the top ten most innovative companies globally and make particular reference to the speed at which they introduce new products and services. As a result, both innovation and efficiency were valued highly. Privacy of staff, however, was not a high priority as the organization had a culture of openness, sharing of ideas and collaboration.

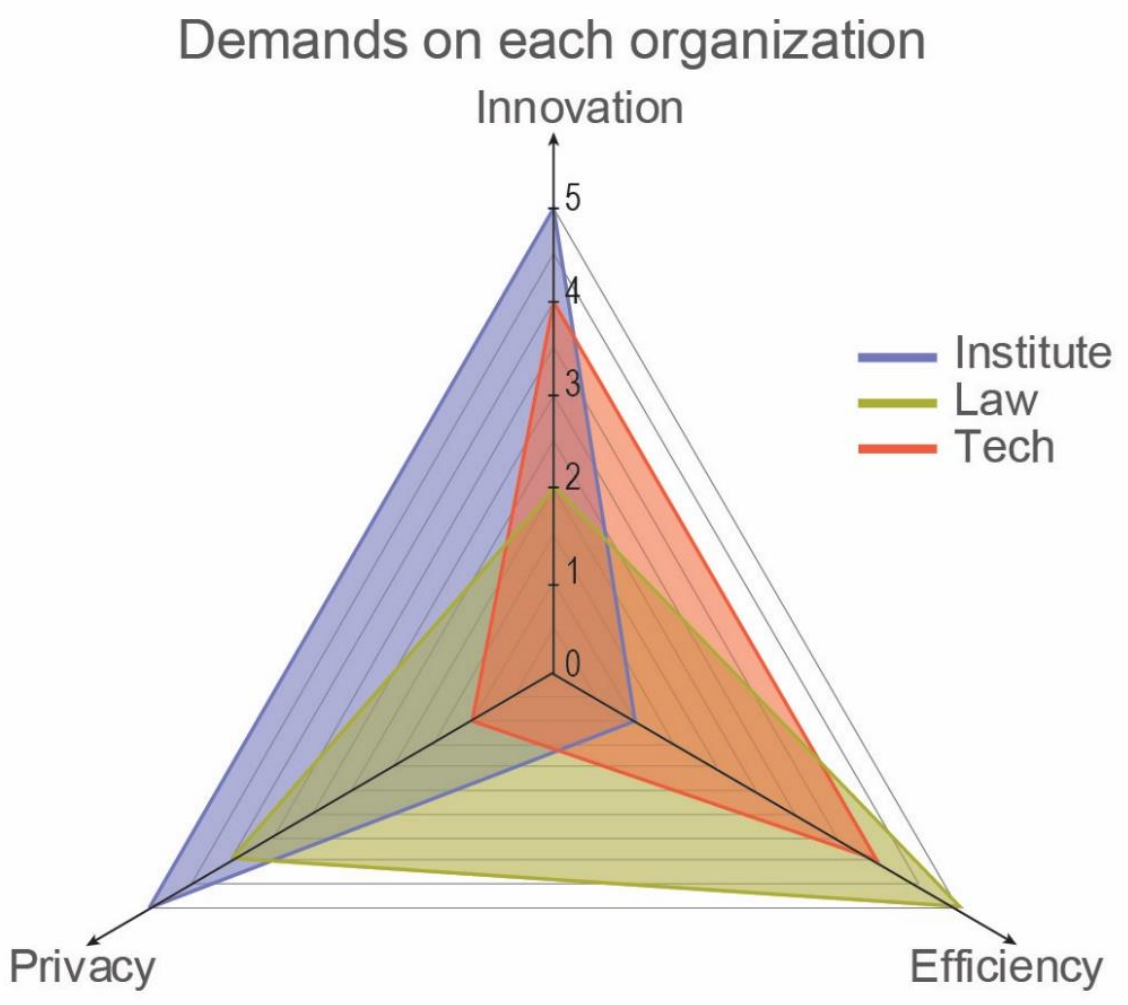

Figure 1: Demands for innovation, efficiency and privacy placed on each organization.

The difference between the three organizations, in terms of the demands placed on them by the nature of their work and competition is shown graphically in figure 1 where there is little overlap in profile.

\section{The socio-spatial environment}

The three studied organizations occupied workplaces with different spatial configurations (cellular versus open), but they also differed regarding the distribution of staff as realized in seating plans (clustered versus distributed).

Figure 2a-c shows the floor plans of each organization overlaid with the seating plan, making those strategic choices obvious of how staff were placed and how that created differential unplanned interaction profiles and potentials. 

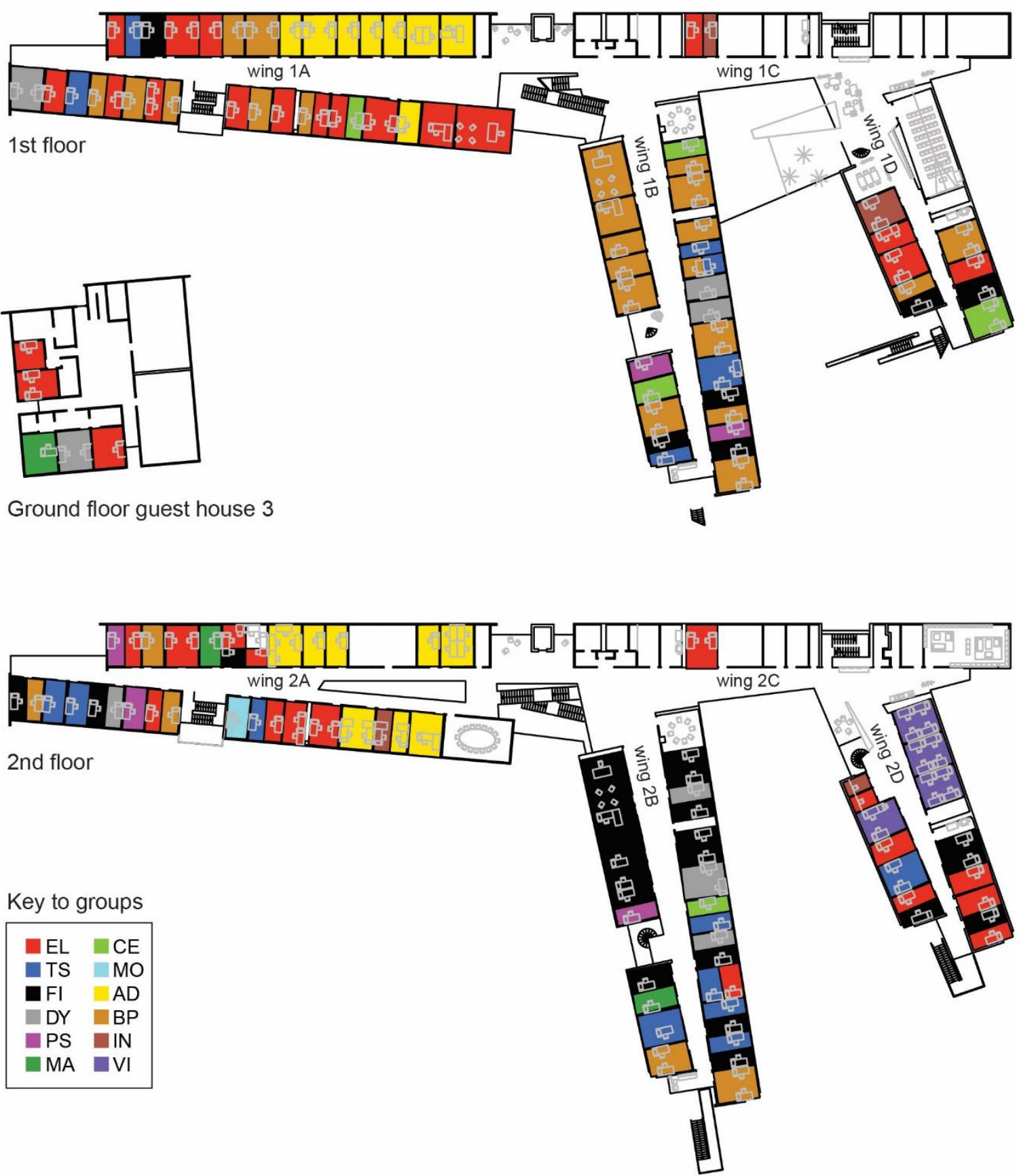

Figure 2a: Floor and seating plans of 'Institute'. The plans were accurate at the time of study. The organization was divided into nine research groups, an admin team (AD), a series of independent researchers (IN) and visitors (VI). 

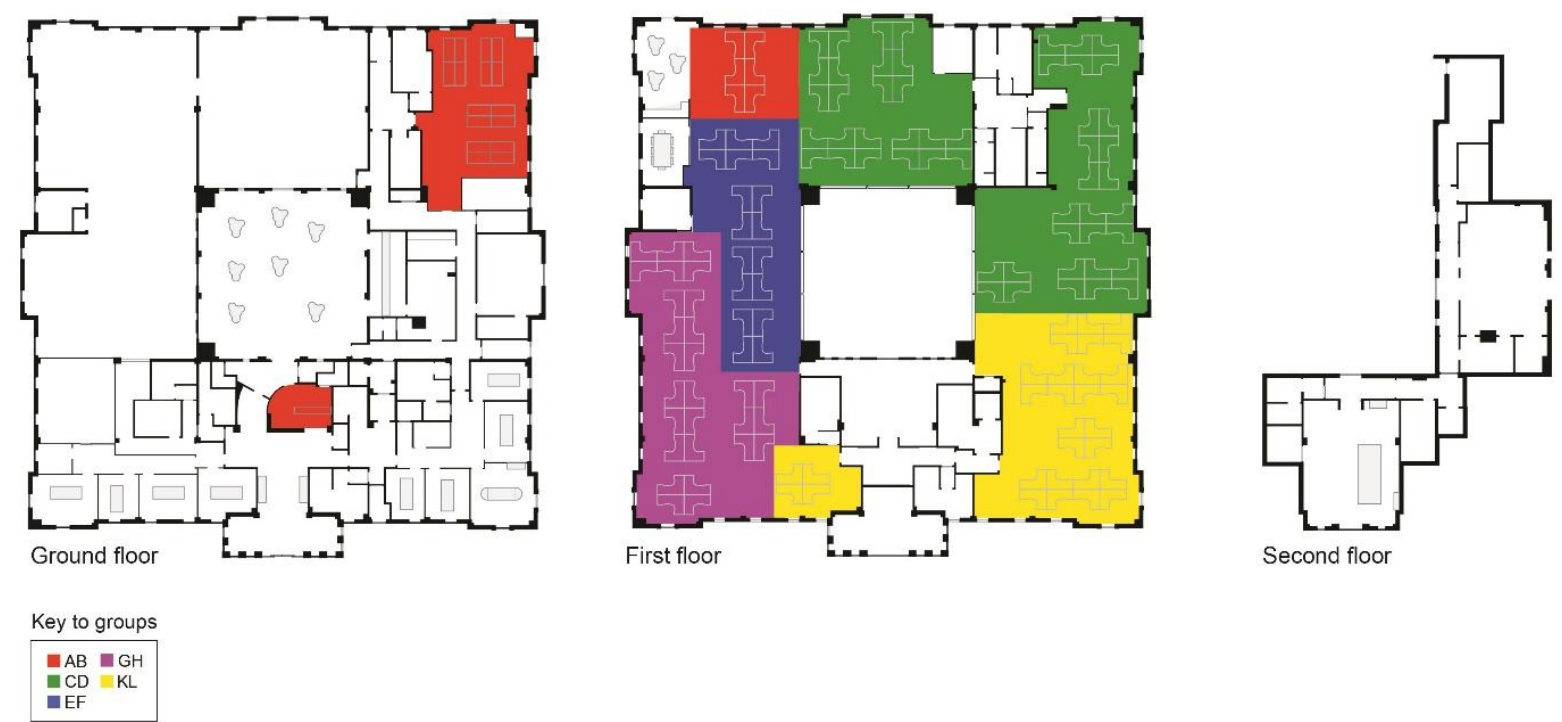

Figure 2b: Floor and seating plans of 'Law'. The plans were accurate at the time of study. The organization was divided into four specialist legal departments supported by an admin team (AB). 

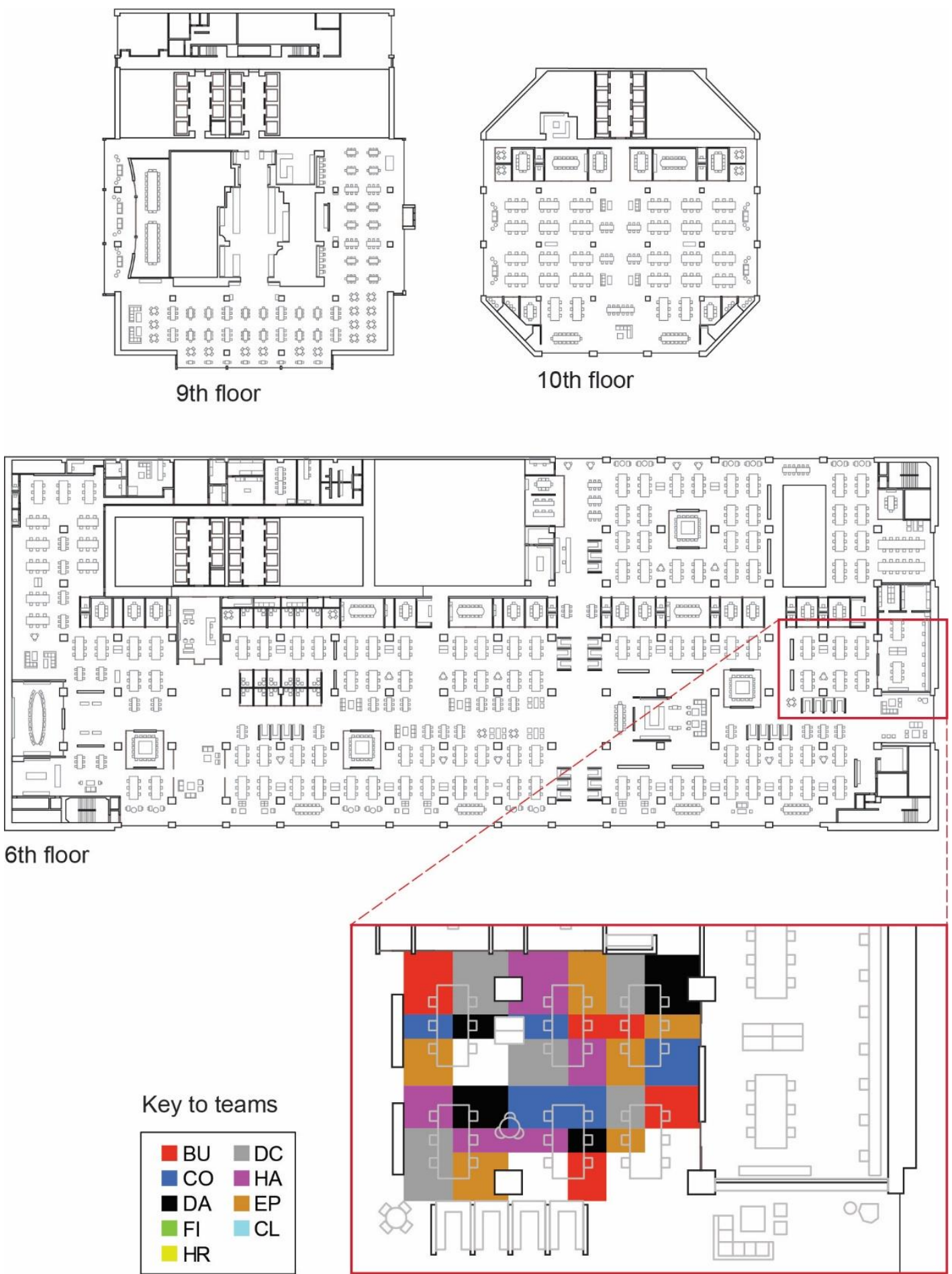

Figure 2c: Floor and seating plans of 'Technology'. The spatialized version of the organization chart reflects the status quo at the time of study, but since it constantly changed, this figure is illustrative only. The organization was divided into nine functional departments of which three were support functions (CL, Fl, HR) and six were technology-driven, seated in 'full-stack' teams.

Table 2 reports on the internal and external correspondence scores calculated for each of the organizations studied. 


\begin{tabular}{|l|c|c|}
\hline Yule's Q & Internal Correspondence & External Correspondence \\
\hline Institute & 0.22 & $(0.23)$ \\
\hline Law & 0.86 & 0.96 \\
\hline Technology & $(0.24)$ & 0.81 \\
\hline
\end{tabular}

Table 2: Internal and External Correspondence by organization

'Institute' shows a score of 0.22 for correspondence internally and -0.23 externally. Both scores are tending towards zero or non-correspondence with the internal score just above zero and external correspondence just below.

In terms of social interaction, this socio-spatial environment suggests that researchers specializing in the same field of theoretical physics are just as likely to interact with researchers from other groups as they are with researchers from their own. In addition, all staff members are more likely to interact with visitors than with other staff members.

'Law' shows scores of 0.86 internally and 0.96 externally. Both scores highlight positive correspondence. This is a socio-spatial environment that will encourage interaction between team members but not with members of other teams and one that will virtually exclude unplanned interaction with visitors.

'Technology' shows scores of -0.24 and 0.81 for internal and external correspondence respectively. Internally, the score is tending towards noncorrespondence, suggesting that staff are slightly more likely to interact with members of other teams rather than their own. However, the external score is tending towards positive correspondence, suggesting that unplanned interaction with visitors is unlikely.

These results challenge some of the taken-for-granted assumptions about open-plan and cellular office layouts. Open-plan offices are assumed to be good at generating unplanned encounter, whereas, results show two contrasting interaction profiles for the two open-plan offices studied. 'Technology' shows non-correspondence internally suggesting that unplanned interaction between staff is encouraged. By contrast, 'Law' shows correspondence internally suggesting that staff interact within their own teams and not with other teams.

In fact, results show that, of the three organizations studied in this paper, it is the layout with cellular offices that encourages the most unplanned interaction between staff. This shows that open-plan is no guarantee of the sort of unplanned encounter known to encourage innovation.

This conclusion is even more apparent when considering the potential for unplanned encounter between staff and outsiders. Both open-plan offices studied put serious constraints on such interactions, as evidenced by the positive external correspondence scores. By contrast, the cellular office studied showed slightly negative non-correspondence externally suggesting an organization that is very porous to outsiders. 
The taken-for granted argument that suggests that open-plan encourages unplanned encounter while cellular impedes it does not hold, because it reduces the analysis to a spatial argument alone. This ignores the impact of conceptual relations between people on interaction.

However, understanding the impact of a socio-spatial layout on interaction is only half of the problem. It is also important to understand whether the resulting interaction profile enables or constrains the demands placed on the organization. In the following section this is considered as the organization-environment fit.

\section{The organization-environment fit}

The interaction profile in 'Institute' was one that encouraged interaction with unlike others as much as it does with similar others. This is the case for unlike others in terms of their research specialism and unlike in terms of their employment by the organization. This sort of interaction profile is known to encourage the crossfertilization that has the potential to result in genuinely novel ideas. Although unplanned interaction is beneficial to innovation, the researchers also require privacy from those interactions in order to be able to read, write, think and calculate. This privacy was afforded by the environment in the form of the cellular offices. The unplanned interaction occurred when people within the building were on the move. The organization ensured that people regularly left their offices through a rich program of public lectures, seminars, sporting events, outings and social gatherings.

As an organization that had a demand for innovation and privacy (see figure 1), 'Institute' appears to have a socio-spatial environment that fits the demands placed on it.

The interaction profile in 'Law' was one that encouraged unplanned interaction within the teams of specialist lawyers but constrained interaction with lawyers from other specialisms as well as visitors to the organization. To produce advice for their clients, lawyers often needed to consult with, or delegate work to, other lawyers that specialized in the same area of law. The high levels of interaction within these specialist teams contributed to the efficiency with which this advice was produced. Unplanned interactions outside of these specialist teams were often seen as a distraction from getting this work done and hence an inefficiency. As a result, the socio-spatial environment in 'Law' appeared to provide a good fit with the demands placed on the lawyers.

The interaction profile in 'Technology' encouraged interaction within and between teams but constrained interaction with outsiders. The unplanned interaction across teams is known to encourage innovation and as such suggests a good fit with the demands placed on the organization. As with 'Law', unnecessary interaction might be seen as a distraction from producing efficiently and the constraint on interaction with visitors might suggest that the demand for efficiency is also met by these sociospatial arrangements.

Overall, results show that there is a recognizable organization-environment fit in all three organizations studied. Using more conventional wisdom about the impact of open-plan and cellular offices would not have resulted in the same conclusion. For 
example, results from 'Institute' challenge the idea that cellular offices are unable to produce the type of unplanned interaction that encourages innovation. In the following section the fallacy of 'open-plan good - cellular bad' is discussed further.

\section{Discussion: The organization-environment fit}

In this discussion of results two different strands of thought are brought together. Firstly, more reflections on open-plan and cellular offices will be offered and secondly, practical implications for managers wishing to use their workplace more strategically to support their organizations will be highlighted.

\section{Open-plan Good - Cellular Office Bad?}

This paper has presented a new way of understanding the impact of the office environment on an organization. This new perspective reveals the mantra of 'openplan good - cellular offices bad' as a fallacy and starts to explain some of the contradictions, paradoxes and inconsistencies evident in research on offices. It can be summarized that neither office form automatically guarantees superiority. Cellular offices can work and so can open-plan layouts.

The American historian Melvin Kranzberg has once famously stated that technology is neither good nor bad; nor is it neutral (Kranzberg, 1986). The same can be said for offices as socio-spatial systems: they are neither good nor bad per se. And they are not neutral either, since they have profound implications on the potentials and opportunities for encounter among different sets of people.

Reframing the issue of open-plan versus cellular offices as a question of fit in order to transcend paradoxes allows a more complex understanding of the intricacies of organizational life (Lewis, 2000). Using a socio-spatial perspective that combines the effects of both spatial and conceptual relations between people, this paper argues that it is wrong to think about office layouts in isolation to the demands being placed on the organization by the nature of the work undertaken.

Three organizations with substantially different office layouts have been presented that showcase a decent fit between these layouts and the demands placed on them. However, this fit is not perfect and in dynamic markets may change over time. In this discussion, some practical challenges that each organization may face are highlighted by the analysis.

Despite the apparent organization-environment fit in 'Technology' described above, the analysis presented here still raises challenging questions for the organization. The positive correspondence externally means that unplanned encounter with people outside of the organization is relatively rare for staff of 'Technology'. The layout of 'Technology' is typical of many of the 'Cathedrals to innovation' (Waber et al., 2014) found in Silicon Valley with large open-plan spaces on remote campuses that seem almost fortified against visitors. They are designed this way primarily because of concerns about the commercial sensitivity of what they are creating, however, such an approach might be a problem in two respects. First, the literature on innovation suggests that genuine novelty requires interaction with people outside of your immediate social network (Padgett and Powell, 2012). Second, these layouts 
potentially isolate the organizations from the very people they are innovating for. Thomas has suggested that this sort of insular innovation might explain some of the "consumer, social and political problems created by some of the world's largest technology companies" (Thomas, 2019, p. 240).

Similarly, the analysis raises questions for 'Law' and 'Institute'. It was shown how the socio-spatial layout in 'Law' encouraged efficiency and enabled privacy as demanded by the organization but also constrained interaction between groups and with visitors, thereby hampering the innovative potential of the organization. This profile highlights areas where the organization - environment fit might not be ideal for 'Law'. For example, cross-selling between specialist legal groups is typically encouraged in law firms, yet the constraints on interaction between groups are likely to discourage this outcome. Similarly, clients of law firms typically demand creative solutions to their problems, and the organization strategy is likely to require innovation, hence it is envisaged that the profile found in 'Law' may, at some points in the firm's development, be problematic.

For 'Institute' it was found that the cellular offices enabled staff to find the levels of privacy they needed, and that the socio-spatial layout more broadly encouraged the type of unplanned encounter known to encourage genuine novelty. However, it was also noted that such encounters only took place when people were on the move. If 'Institute's extensive program of activities was less popular or was reduced due to the considerable efforts required and people using 'Institute' chose to stay in their offices more, the frequency of interaction with others would be reduced. The effect of this is likely to be a reduction in the rate of innovation.

The analysis suggests that all three of the studied organizations face challenges, either now or in the future. Whether the organizations realize it or not, their office layouts are compromises that trade-off one organizational objective with another.

\section{Practical implications: The Probability Game}

The approach presented in this paper offers a series of practical opportunities for managers to increase the efficacy of people at work. Managers are used to thinking of the strategic design of organizations as a key concern yet may not consider the physical workspace as an equally important strategic management tool at the same time. Rather than seeing physical space and organizational structure as two separate management tools as previous research suggested (Allen and Henn, 2006), this paper proposes treating them as a single lever.

The concept of correspondence allows managers to not only think of workplace design choices (such as openness of the workplace, or degree of partitioning), but to consider how organizational structure manifested in space by seating plans, often decided without conscious thought, brings those opportunities built into the physical fabric of an office to life. Who should meet whom how often and in what spatial circumstances?

This paper suggests thinking of the overlap of physical design of the workplace and the organizational chart as a probability game. The seating plan, i.e. the spatialized version of the organizational structure in conjunction with the distribution of everyday resources (meeting rooms, tea points, entrances, toilets etc.) creates an opportunity 
structure of encounters. Research has shown that the majority of movement in the office can be explained by the layout structure plus the placement of attractors (Sailer, 2007), while watercoolers and printers create affordances for interaction (Fayard and Weeks, 2007). The likelihood of bumping into others is strongly associated with the physical configuration of the office, for instance if everyday paths lead alongside desks (Backhouse and Drew, 1992). This has also been called 'collisionable hours', a metric designed to measure the density potential to meet others (Waber et al., 2014).

Therefore practical implications range from the easy - including reconsidering the location of movable resources (where to plug in the good coffee machine), the distribution or clustering of attractors (meeting room suite versus more localized meeting rooms), and the distribution of teams (clustered or randomized) - to the more impactful including a change to the physical structure of the workplace, or even an office move.

This means managers can play the probability game by maximizing the chances of generative encounters between relevant groups of people, thus designing a noncorrespondent system, if innovation is a required output. If efficiency or confidentiality is more valued, a more correspondent system may provide the better fit.

\section{Conclusions}

In this paper three organizations and their socio-spatial systems of organizing and structuring work were studied as an effect of the overlap of workplace layouts and the organization structure.

Against the background of continued inconsistencies of the effects of open-plan layouts on work patterns as evident by contradictory and inconclusive research evidence to date, three major innovations were suggested: firstly, to consider configurational details of offices, secondly, to analyze spatial and social relations simultaneously and thirdly, to investigate the organization-environment fit.

The first was achieved by analyzing the shortest paths that people take through the office from their desk creating dynamic patterns of closeness to different kinds of colleagues - those conceptually close, thus belonging to someone's own team or group, versus those conceptually distant from another group or team.

The second innovation was achieved by introducing and applying correspondence theory. Calculating the degree of boundary maintenance in the three studied organizations via the single metric of the Yule's $Q$ showed how open and porous boundaries were for the organizations, both internally between teams and externally towards visitors.

The third innovation was achieved by bringing the environmental and competitive demands placed on the three organizations together with their relative correspondence or non-correspondence and highlighted how all three cases showed a relatively good fit between organization and environment, notwithstanding potential challenges faced.

As every piece of research, this work has limitations, too. A limited number of cases was studied, and it would be useful to analyze a larger sample of open-plan and cellular offices, potentially with the aim of creating a more systematic overview of 
design choices (strategic organization design and physical workspace design) in relation to demands placed on organizations to create a taxonomy of organizationenvironment fit categories. It could be worthwhile to include cases where a poor organization-environment fit is expected. Selecting cases with known problems, for instance evident by low workplace satisfaction ratings would be an interesting endeavor. Further research could also examine which changes could be made to the socio-spatial system of poorly performing organizations in order to improve organization-environment fit.

It can be concluded that there is probably no such thing as the perfect office layout because optimizing for one demand on the organization might mean compromising on another. However, this paper would argue that these trade-offs should be made consciously, and that the socio-spatial perspective presented in this paper provides the tools for making such critical decisions.

\section{References}

Aldrich, H. E. (1979) Organizations and Environments. Englewood Cliffs/NJ: Prentice-Hall. Allen, T. J. and Henn, G. (2006) The Organization and Architecture of Innovation. Managing the Flow of Technology. Amsterdam/Boston/Heidelberg/London: ButterworthHeinemann.

Appel-Meulenbroek, R., Le Blanc, P. and de Kort, Y. (2020) 'Person-Environment Fit. Optimizing the physical work environment', in Ayoko, O.B. \& Ashkanasy, N.M. (eds.) Organizational Behaviour and the Physical Environment. London and New York: Routledge, pp. 251-267.

Ashkanasy, N. M., Ayoko, O. B. and Jehn, K. A. (2014) 'Understanding the physical environment of work and employee behavior: An affective events perspective', Journal of Organizational Behavior, 35(8), pp. 1169-1184.

Ayoko, O. B. and Ashkanasy, N. M. (eds.) (2020) Organizational Behaviour and the Physical Environment. London and New York: Routledge.

Backhouse, A. and Drew, P. (1992) 'The design implications of social interaction in a workplace setting,' Environment and Planning B: Planning and Design, 19, pp. 573584.

Bari, S. (2015) 'Workspaces: why academics need a room of their own', Times Higher Education Magazine.

Becker, F. (1981) Work Space: Creating Environments in Organizations. New York: Praeger Publishers Inc.

Bernstein, E. S. and Turban, S. (2018) 'The impact of the 'open' workspace on human collaboration', Philosophical Transactions of the Royal Society B: Biological Sciences, 373(1753).

Beunza, D. and Stark, D. (2004) 'Tools of the trade: the socio-technology of arbitrage in a Wall Street trading room', Industrial and Corporate Change, 13(2), pp. 369-400.

CarusoStJohnArchitects (2014) 'A short history of the development of the office', A\&T: Independent Magazine of Architecture and Technology, 43(Spring 2014), pp. 122143.

Clegg, S. R. and Kornberger, M. (eds.) (2006) Space, Organizations and Management Theory. Malmö/Herndon: Liber \& Copenhagen Business School Press.

Davis, T. R. V. (1984) 'The Influence of the Physical Environment in Offices', The Academy of Management Review, 9(2), pp. 271-283.

Elsbach, K. D. and Pratt, M. G. (2007) 'The Physical Environment in Organizations', The Academy of Management Annals, 1(1), pp. 181-224. 
Fayard, A.-L. and Weeks, J. (2007) 'Photocopiers and Water-coolers. The Affordances of Informal Interaction', Organization Studies, 28(5), pp. 605-634.

Gallup (2017) State of the Global Workplace, New York: Gallup Press.

Gieryn, T. F. (2002) 'What buildings do', Theory and Society, 31(1), pp. 35-74.

Hillier, B. (1996) Space is the machine. A configurational theory of architecture. Cambridge. Online at: http://eprints.ucl.ac.uk/3881/: Cambridge University Press.

Hillier, B. and Hanson, J. (1984) The social logic of space. Cambridge: Cambridge University Press.

Hillier, B. and Penn, A. (1991) 'Visible Colleges: Structure and Randomness in the Place of Discovery', Science in Context, 4(1), pp. 23-49.

Irving, G. L., Ayoko, O. B. and Ashkanasy, N. M. (Forthcoming) 'Collaboration, Physical Proximity and Serendipitous Encounters: Avoiding collaboration in a collaborative building', Organization Studies.

Kim, J. and de Dear, R. (2013) 'Workspace satisfaction: The privacy-communication tradeoff in open-plan offices', Journal of Environmental Psychology, 36(0), pp. 18-26.

Kim, J. and De Dear, R. (2020) 'Employee Satisfaction and the Quality of Workplace Environment', in Ayoko, O.B. \& Ashkanasy, N.M. (eds.) Organizational Behaviour and the Physical Environment. London and New York: Routledge, pp. 96-112.

Kranzberg, M. (1986) 'Technology and History: "Kranzberg's Laws"', Technology and Culture, 27(3), pp. 544-560.

Leesman (2019) The Leesman Review, Issue 27, London.

Lewis, M. W. (2000) 'Exploring Paradox: Toward a More Comprehensive Guide', The Academy of Management Review, 25(4), pp. 760-776.

Mark, G. (2002) 'Extreme Collaboration', Communications of the ACM, 45(6), pp. 89-93.

Miles, R. E. and Snow, C. C. (1984) 'Fit, Failure and the Hall of Fame', California Management Review, 26(3), pp. 10-28.

Orlikowski, W. J. and Scott, S. V. (2008) 'Sociomateriality: Challenging the Separation of Technology, Work and Organization', The Academy of Management Annals, 2(1), pp. 433-474.

Padgett, J. F. and Powell, W. W. (2012) The emergence of oganizations and markets. Princeton / NJ: Princeton University Press.

Peters, T. (1990) 'Get Innovative or Get Dead, Part One', California Management Review, 33(1, Fall 1990), pp. 9-26.

Pfeffer, J. (1982) Organizations and Organization Theory. Cambridge MA: Ballinger.

Price, I. (2007) 'Lean Assets: New Language for New Workplaces', California Management Review, 49(2), pp. 102-118.

Propst, R. (1968) The office - a facility based on change, Elmhurst, Illinois, USA: Business Press.

Sailer, K. 'Movement in workplace environments - configurational or programmed?', 6th International Space Syntax Symposium, Istanbul, 12-15 June 2007: ITÜ Faculty of Architecture.

Sailer, K. (2010) The space-organisation relationship. On the shape of the relationship between spatial configuration and collective organisational behaviours. Doctoral Dissertation PhD, Technical University of Dresden, Dresden [Online] Available at: http://nbn-resolving.de/urn:nbn:de:bsz:14-qucosa-38427 (Accessed.

Sailer, K. and Penn, A. 'Spatiality and transpatiality in workplace environments'. 7th International Space Syntax Symposium, Stockholm, Sweden: Royal Institute of Technology KTH, 095:01 - 095:11.

Sailer, K. and Thomas, M. 'Correspondence and Non-Correspondence. Using office accommodation to calculate and organization's propensity for new ideas'. 12th International Space Syntax Symposium, Beijing, China, 166:1 - 166:17.

Savills (2019) What Workers Want 2019: Europe, London: Savills plc Commercial Research. Small, M. L. and Adler, L. (2019) 'The Role of Space in the Formation of Social Ties', Annual Review of Sociology, 45(1). 
Smith, W. K. and Lewis, M. W. (2011) 'Toward a theory of paradox: A dynamic equilibrium model of organizing', The Academy of Management Review, 36(2), pp. 381-403.

Steele, F. I. (1973) Physical Settings and Organization Development. Reading, Mass.: Addison-Wesley.

Sundstrom, E. (1986) Work places: The psychology of the physical environment in offices and factories. Cambridge: Cambridge University Press.

Sundstrom, E., Burt, R. E. and Kamp, D. (1980) 'Privacy at Work: Architectural Correlates of Job Satisfaction and Job Performance', The Academy of Management Journal, 23(1), pp. 101-117.

Thomas, M. (2019) How space affects emergent strategy: A study of the role physical space plays in the generation of social interaction in organisations. PhD, Lancaster University, Lancaster, UK.

Tsen, P.-R. (2001) 'Viewing the Market: The Architectural Design of Trading Rooms in the Interplay between Face-To-Face Communication and Face-To-Screen Communication', The Journal of Space Syntax, 2(1), pp. 54-72.

Van den Ende, L., Willems, T. and Van Marrewijk, A. (2020) 'Socio-Materiality and the Physical Environment of Organizations', in Ayoko, O.B. \& Ashkanasy, N.M. (eds.) Organizational Behaviour and the Physical Environment. London and New York: Routledge, pp. 200-213.

Van Marrewijk, A. and Van den Ende, L. (2018) 'Changing academic work places: the introduction of open-plan offices in universities', Journal of Organizational Change Management, 31(5), pp. 1119-1137.

Waber, B., Magnolfi, J. and Lindsay, G. (2014) 'Workspaces That Move People', Harvard Business Review, (October 2014).

\footnotetext{
' https://www.ft.com/content/8c9fb7c2-1856-11e9-9e64-d150b3105d21 (Last accessed: 30 Jul 2019)

ii https://www.vice.com/en uk/article/j54gv4/open-plan-offices-should-be-banned-immediately (Last accessed: 30 Jul 2019)

iii https://www.theguardian.com/lifeandstyle/2018/nov/09/oliver-burkeman-this-column-open-planoffices (Last accessed: 30 Jul 2019)

iv https://www.forbes.com/sites/stephaniesarkis/2019/01/27/how-your-open-plan-office-is-killing-yourprivacy-and-safety/\#284d731e4e99 (Last accessed: 30 Jul 2019)

v https://www.fastcompany.com/90170941/the-subtle-sexism-of-your-open-plan-office (Last accessed: 30 Jul 2019)

vi https://www.theguardian.com/news/2013/nov/18/open-plan-offices-bad-harvard-business-review

(Last accessed: 2 Sep 2019)

vii It was counted a) how many members of staff were spatially close and conceptually close to one another; b) how many were spatially distant, but conceptually close; c) how many were spatially close, but conceptually distant; and d) how many were spatially and conceptually distant. From this Yule's $Q$ was calculated through the formula: Yule's $Q=(a \times d-b \times c) /(a \times d+b \times c)$.

viii All direct quotes are from interviews.
} 